\title{
O OBSERVATÓRIO NACIONAL E A COOPERAÇÃO ENTRE CONSELHOS JUDICIAIS E MINISTERIAIS NỎ BRASIL
}

\section{THE NATIONAL OBSERVATORY AND THE COOPERATION BETWEEN JUDICIAL COUNCILS IN BRAZIL}

\author{
KARINA DENARI GOMES DE MATTOS ${ }^{1}$ \\ LINCOLN ANTÔNIO ANDRADE DE MOURA ${ }^{2}$ \\ GUILHERME BALBI ${ }^{3}$
}

RESUMO: Os Conselhos Nacionais de Justiça (CNJ) e do Ministério Público (CNMP) no Brasil, instituídos por força da Emenda Constitucional nº 45/2004, são parte de um movimento global de fortalecimento dos mecanismos institucionais que visam a ampliação da transparência e efetividade das instituições do sistema de justiça, ao mesmo tempo que visam garantir sua autonomia e independência face a outros poderes. A criação de Conselhos Judiciais também caminha lado a lado com a tendência cada vez mais forte de aproximação do sistema de justiça com a opinião pública e pela busca de uma maior legitimidade. No Brasil, o Observatório Nacional sobre Questões Ambientais, Econômicas e Sociais de Alta Complexidade e Grande Impacto e Repercussão, criado em 2019 em parceria pelo CNJ e CNMP, se apresenta como uma iniciativa inédita tanto para a consolidação do modelo de atuação dos Conselhos quanto para a aproximação estratégica entre Judiciário e Ministério Público, além da prestação de contas à sociedade. O

\footnotetext{
${ }^{1}$ Doutora em Direito pelo Programa de Pós-Graduação em Direito da Universidade Federal do Rio de Janeiro. Mestre em Direito do Estado pela Faculdade de Direito da Universidade de São Paulo. Pesquisadora Sênior do Centro de Direitos Humanos e Empresas da Fundação Getúlio Vargas - CeDHE (FGV DIREITO SP) e Pesquisadora Conveniada do Núcleo de Constituição e Justiça da Fundação Getulio Vargas NJC (FGV DIREITO SP). Professora substituta do Departamento de Teoria do Direito da Faculdade Nacional de Direito (UFRJ).

${ }^{2}$ Mestre em Direito e Desenvolvimento pela FGV. Pós-graduado em Direito Civil e Direito Imobiliário. Graduado em Direito pela Universidade Presbiteriana Mackenzie. Professor nas Faculdades Integradas de Guarulhos - FIG/UNIMESP. Juiz de Direito no TJSP. Pesquisador permanente no Núcleo de Constituição e Justiça da Fundação Getulio Vargas NJC (FGV DIREITO SP).

${ }^{3}$ Mestrando em Direito pela Faculdade de Direito da USP. Graduação em Direito pela Universidade de São Paulo. Pesquisador e membro do grupo Núcleo de Constituição e Justiça da Fundação Getulio Vargas NJC (FGV DIREITO SP). Professor colaborador da Sociedade Brasileira de Direito Público (SBDP).
} 
presente trabalho visa descrever essa instância interinstitucional após dois anos de execução de suas atividades e questionar seus impactos, especialmente em termos de ganho de legitimidade e transparência na prestação de informações à sociedade.

PALAVRAS-CHAVE: judiciário; ministério público; conselho; legitimidade.

ABSTRACT: The National Council of Justice (CNJ) and the National Public Prosecutor's Council (CNMP) in Brazil, instituted by the Constitutional Amendment No. 45/2004, are part of a global movement to strengthen the institutional mechanisms aimed at increasing the transparency and effectiveness of institutions of the justice system, while guaranteeing its autonomy and independence from other powers. The creation of Councils also follows the growing trend of bringing the justice system closer to public opinion and reflects the pursuit for a greater legitimacy. In Brazil, the "National Observatory on Environmental, Economic, and Social Issues of High Complexity and Great Impact", created in 2019 in partnership by the CNJ and CNMP, presents itself as an unprecedented initiative both for the consolidation of the acting model of the Councils, in terms of strategic relationship between Judges and Prosecutors and accountability to society. This work aims to describe this inter-institutional instance after two years of its implementation and reflect on its current impacts, especially in terms of legitimacy and transparency in its relation with the civil society.

KEYWORDS: judiciary bench; public prosecutor's office; council; legitimacy.

\section{INTRODUÇÃO}

No dia 31 de janeiro de 2019, o Conselho Nacional do Ministério Público (CNMP) e o Conselho Nacional de Justiça (CNJ), por meio da Portaria Conjunta n. 01/2019, instituíram o Observatório Nacional sobre Questões Ambientais, Econômicas e Sociais de Alta Complexidade e Grande Impacto e Repercussão (doravante, "Observatório"). Conforme exposto no respectivo site, a finalidade do Observatório é, em suma, promover o aperfeiçoamento da atuação das instituições em ocorrências de grande impacto e repercussão, incluindo a implantação e modernização de rotinas, prioridades, organização, especialização e estruturação dos órgãos competentes de atuação do Poder Judiciário e do Ministério Público.

A iniciativa se mostra inovadora em âmbito nacional por permitir a atuação conjunta dos órgãos administrativos de controle das carreiras da Magistratura e do Ministério Público em contextos de profunda complexidade. Ela denota, assim, 
POLÍTICOS

um esforço institucional de articulação no sistema de justiça e uma compreensão de que tais desafios dependem de uma complexa rede de esforços para seu correto enquadramento e resolução.

Se analisada a iniciativa do Observatório frente a outros países, ela se torna ainda mais interessante e rica. A própria criação de Conselhos Judiciais é um movimento recente, próprio de democracias constitucionais, e associado à necessidade de incremento da autonomia de gestão e auto-organização dos órgãos do sistema de justiça; a conjugação de esforços entre Conselhos Judiciais, aqui exposta, é ainda mais recente, e potencialmente inédita nas democracias ocidentais.

Nuno Garoupa e Tom Ginsburg afirmam que diversas jurisdições adotaram instituições conhecidas como Conselhos Judiciais nos últimos anos, uma "boa prática" desenhada para ajudar a assegurar tanto a independência judicial quanto uma prestação de contas e transparência (external accountability) - e encontrar um equilíbrio entre ambas (GAROUPA, GINSBURG, 2008, p. 3). Hoje aproximadamente $60 \%$ dos países contam com uma estrutura de Conselho Judicial - diferentemente de 30 anos atrás, quando eles estavam presentes em apenas 10\% dos países analisados (GAROUPA, GINSBURG, 2008, p. 3). Tais estruturas possuem funções que vão desde a seleção, promoção e remoção de juízes até a administração da justiça (HAMMERGREN, 2002).

No caso do Brasil, ainda que a criação dessa estrutura remeta ao ano de 1977 (Emenda Constitucional no 7/1977), o Conselho Nacional de Justiça (CNJ) na sua formatação atual - com uma função igualmente importante de transparência e acesso à informação, além da disciplinar - foi criado pela Emenda Constitucional no 45/2004 (Emenda da Reforma do Judiciário). Na mesma Emenda Constitucional foi criado o Conselho Nacional do Ministério Público (CNMP), como se verá a seguir, replicando, ao Ministério Público, essa organização em Conselhos.

Verifica-se, portanto, do ponto de vista comparado e, especialmente, da perspectiva histórica que, se num primeiro momento a criação de Conselhos Judiciais era dedicada a reforçar a independência e autonomia gerencial e disciplinar de seus membros, ainda sob os fantasmas de regimes autoritários das décadas anteriores, hoje parece que tais estruturas passaram a ter um papel cada vez mais presente de transparência, monitoramento e accountability externos, por meio das quais o Judiciário presta contas à sociedade e adquire capital social e político. Todavia, especialmente se olharmos a realidade brasileira, essas novas funções apresentam também desafios igualmente relevantes, em especial consequências que podem ter impacto na própria atuação e função institucional de seus membros - o que poderia inclusive gerar incentivos contraproducentes.

Nessa linha, o surgimento de mais uma instância ${ }^{4}$ de monitoramento e prestação de contas à sociedade ${ }^{5}$ no Brasil, a se somar à estrutura já existente -

\footnotetext{
${ }^{4}$ A Portaria Conjunta CNJ/CNMP no 01/2019 prevê no art. 3ํo a lista de membros e observadores que compõem a entidade.
} 
igualmente voltada para o aperfeiçoamento da atuação ministerial e judicial causa perplexidade. Ainda que críticas possam ser levantadas contra as Corregedorias Gerais de Justiça e do Ministério Público que compõem o CNJ e o CNMP, a exemplo do que fazem Kerche, Oliveira e Couto (2020) e Franco e Cunha (2013), era de se esperar que as estruturas de controle habilitadas pelos Conselhos Nacionais fossem suficientes para superá-las. Este contexto faz surgir a questão central deste estudo: por que o Observatório foi criado - ou, em outras palavras, quais as principais razões que potencialmente justificam essa iniciativa?

Para dar resposta a essa indagação, este estudo opta pela metodologia qualitativa do estudo de caso para debruçar-se sobre o desenho institucional do Observatório - mediante a análise de sua estrutura normativa e sua composição, delineadas pela Portaria Conjunta CNJ/CNMP no 1/2019 -, bem como suas reformulações internas e ações adotadas por ele nos primeiros anos de exercício. A análise documental aqui realizada partiu de um enfoque descritivo, dada a inexistência de estudos sobre o tema e os ganhos analíticos que uma proposta nessa linha pode trazer para futuros estudos sobre a cooperação institucional entre CNJ e CNMP.

Observa-se dos documentos mapeados, sobretudo, a justificativa para a criação do Observatório, os critérios utilizados para a escolha dos casos e os espaços de participação social previstos. Dadas as sucessivas alterações nas escolhas dos temas desde 2019, também se investiga em que medida o clamor social muda as perspectivas de monitoramento e qual o nível de participação social no desenho e na dinâmica dessas atividades.

O resultado obtido revela que a criação do Observatório não está necessariamente voltada ao aperfeiçoamento da atuação ministerial ou judicial, mas principalmente se centra na obtenção de apoio junto à opinião pública. $\mathrm{O}$ Observatório, a partir da análise de seu desenho e execução até o momento, constitui um órgão de comunicação e aproximação do Judiciário e do Ministério Público com a sociedade, e assim, destinado ao ganho de legitimidade em favor de seus membros.

A premissa de que a criação do Observatório seria estratégica para a obtenção do apoio da opinião pública está pautada em Jeffrey Staton, (2010), que estudou o uso de estratégias de comunicação com a sociedade, pela Suprema Corte Mexicana, para se impor ao Poder Executivo (caso Zedillo).

Jeffrey Staton (2010) desenvolve tese a respeito das estratégias de comunicação adotadas pelo Supremo Tribunal mexicano para obter o apoio da opinião pública e, com isto, ver reconhecida a sua legitimidade para o enfretamento com o

\footnotetext{
${ }^{5} \mathrm{O}$ Observatório soma-se a outras iniciativas de prestação de contas e aperfeiçoamento do trabalho em temas complexos, aproximando a atuação do Judiciário e do Ministério Público da sociedade. Como exemplo a recente criação do Observatório de Direitos Humanos em setembro de 2020 pelo CNJ, dentre outros órgãos nessa linha. Disponível em: https://www.cnj.jus.br/observatorio/observatorio-direitos-humanos/ . Acesso em 04 abr. 2021.
} 
POLÍTICOS

governo Zedillo. O autor teoriza a respeito do uso que juízes constitucionais fazem da mídia em todos os aspectos: ao comunicar seus resultados decisórios, ao clarificar seus argumentos ou mesmo por meio de entrevistas e esclarecimentos mais amplos sobre o seu papel institucional e fortalecimento do órgão. Ao analisar a relação dos Judiciários com a mídia ao redor do mundo, o autor sustenta que as Cortes da América Latina adotaram "estratégias de relações públicas particularmente agressivas" (STATON, 2010, p. 4, tradução nossa).

Neste contexto, o estudo pretende verificar, empiricamente, as distintas funções cumpridas pelo Observatório e se há um exercício de promoção e comunicação nos Conselhos Nacionais análogo ao observado por Staton (2010) no âmbito da Corte Mexicana. Ao fazê-lo, busca contribuir com as discussões internacionais sobre esses importantes órgãos que são os Conselhos Nacionais sejam os judiciais ou ministeriais, na linha também de outros estudos publicados recentemente no país sobre o tema (KERCHE, OLIVEIRA, COUTO, 2020; KOZAK, BARBOZA, 2020).

$\mathrm{O}$ estudo de caso apresenta-se como relevante e pertinente no estudo sobre instituições do sistema de justiça, visto que a criação do Observatório no ano de 2019 vem a se somar aos esforços de compreensão contemporânea sobre o papel de Conselhos Judiciais como estruturas de transparência e prestação de contas. Além disso, o Observatório deriva de uma parceria de dois Conselhos criados pela EC 45/2004, o CNJ e o CNMP - o que parece ser uma tendência de aproximação das instituições do sistema de justiça no fortalecimento cruzado de suas funções e apoio institucional. Por fim, mostra-se que o Observatório também tem cada vez mais se apoiado em ferramentas tecnológicas e investimento em monitoramento de decisões e atos para ampliar essa relevante missão.

Esse artigo é composto por três seções: a apresentação da estrutura normativa e composição do Observatório, uma exposição das boas-práticas e soluções apresentadas e, por fim, uma análise crítica de seus pressupostos e execução.

\section{O OBSERVATÓRIO: ESTRUTURA NORMATIVA E COMPOSIÇÃO}

Conforme informações lançadas no site do Conselho Nacional de Justiça, o Observatório Nacional sobre Questões Ambientais, Econômicas e Sociais de Alta Complexidade, Grande Impacto e Repercussão foi criado após o rompimento da barragem de rejeitos controlada pela Vale S/A em Brumadinho no dia 25 de janeiro de 2019, desastre que culminou com a morte de 259 pessoas e o desaparecimento de outras 11, além da destruição socioambiental e socioeconômica na região.

Segundo o Min. Dias Toffoli, a instituição do Observatório - que se deu seis dias após a tragédia ambiental - teria a finalidade de:

[...] conferir agilidade e rapidez às respostas do Judiciário não só nas questões relativas à calamidade de Brumadinho, mas a outros grandes acidentes com 
vítimas fatais, impactos socais e danos ambientais que ainda estão sem a devida resposta das instâncias judiciais." (CNJ, 2019).

Para a Procuradora Geral da República e presidente do Conselho Nacional do Ministério Público de então, Raquel Dodge, a iniciativa teria o condão de '[...] elevar a credibilidade das pessoas e da sociedade brasileira em relação ao sistema de justiça" (BRASIL, 2019).

Nos Considerandos do ato de sua criação, constam a (i) a finalidade de viabilizar "[...] o acesso à justiça para os cidadãos atingidos por catástrofes ambientais", (ii) a menção ao fato de que questões de "[...] grande repercussão ambiental, econômica e social [...]" deveriam ter "[...] atenção prioritária do Poder Judiciário e do Ministério Público", assim como a "[...] proteção da água, da vida, dos direitos humanos e do ambiente" (BRASIL,2019a).

Conforme o exposto no art. $2^{\underline{0}}$ da Portaria em alusão, caberia ao Observatório, em suma, o (i) levantamento de dados estatísticos; (ii) o monitoramento do andamento processual e das soluções aos casos de grande impacto e repercussão; (iii) a propositura de medidas para aperfeiçoamento dos procedimentos em busca da solução do conflito; (iv) a promoção da integração entre membros do Poder Judiciário, do Ministério Público e de outras instituições nacionais e internacionais.

Composto originalmente por 14 membros, todos integrantes do CNJ e do $\mathrm{CNMP}^{6}$, o Observatório passou a contar, a partir de 11 de novembro de 2019, com a participação do Advogado-Geral da União, do Defensor Público-Geral Federal e do Presidente da OAB, todos com status de observadores (BRASIL, 2019b). A sua atuação consistiria na emissão de relatórios trimestrais, cujos teores versariam sobre as suas atividades ${ }^{7}$.

\subsection{Análise exploratória sobre o desenho proposto}

O primeiro ponto de questionamento sobre a pertinência do Observatório é o fato de ele não ser uma ideia nova: dos Considerandos lançados na Portaria Conjunta n. 01/2019 que levou à sua criação consta a menção ao relatório Justiça Plena, originário do CNJ e referente às “[...] causas de grande repercussão social no Poder Judiciário, bem como o Projeto SINALID - Sistema Nacional de

\footnotetext{
${ }^{6}$ Conforme o art. $3^{\text {o }}$ da Portaria Conjunta no 1 CNJ/CNMP, os 14 membros do Observatório seriam: dois Conselheiros do Conselho Nacional de Justiça; dois Conselheiros do Conselho Nacional do Ministério Público; o Secretário-Geral do Conselho Nacional de Justiça; o Secretário-Geral do Conselho Nacional do Ministério Público; o Secretário Especial de Programas, Pesquisas e Gestão Estratégica do Conselho Nacional de Justiça; três Juízes Auxiliares no CNJ; e quatro membros do Ministério Público atuantes no Conselho Nacional do Ministério Público.

${ }^{7}$ Art. $4^{\circ}$ O Observatório deverá apresentar relatórios trimestrais de suas atividades. Para visualizar o conjunto de relatórios produzidos pelo Observatório, a consulta ao site institucional (BRASIL, 2021 [site institucional]).
} 
POLÍTICOS

Localização e Identificação de Pessoas Desaparecidas ${ }^{8}$, do Projeto Água, Vida, Floresta e Direitos Humanos ${ }^{9}$ e do Projeto Água para o Futuro ${ }^{10^{\prime \prime}}$.

Desse modo, essa união de esforços entre os Conselhos, destinada ao acompanhamento de casos de grande repercussão, remonta ao ano de $2010^{11}$. Com o advento do Observatório Nacional, o relatório Justiça Plena foi extinto e os seus casos ativos foram encaminhados ao Observatório:

Em razão da necessidade de otimizar os recursos do Poder Judiciário e promover o aperfeiçoamento da Governança e da Gestão, foi deliberado pelo Comitê Gestor dos Cadastros Nacionais (CGCN) a extinção do projeto e o consequente encaminhamento dos processos ativos ao Observatório Nacional para analisar a pertinência de inclusão no sistema (BRASIL, 2021).

Em relação a tais iniciativas conjuntas, salta aos olhos a inexistência de previsão constitucional ou legal para a sua criação, sendo criados por Portaria Conjunta. Esta característica faz com que a sua estrutura e composição possam ser alteradas com celeridade, fato este que pode ser algo positivo ou negativo, conforme o escopo efetivamente perseguido pelas instituições.

Assim, para descobrir as demais finalidades almejadas com a criação do Observatório, o primeiro ponto é entender, para além das metas institucionais definidas na Portaria, como sua criação está imediatamente relacionada com a

8 Criado em 2010, o SINALID teria por finalidade enfrentar o problema relativo ao desaparecimento de pessoas. Sua atuação visaria “[...] a articulação de várias órgãos e agentes públicos em torno de uma política nacional de descoberta de paradeiros". O SINALID seria gerido pela Comissão de Defesa dos Direitos Fundamentais (CDDF) e, regionalmente, pelos Programas de Localização e Identificação de Desaparecidos (PLIDs). O Sinalid seria integrado “[...] por milhares de usuários do Ministério Público, da segurança pública, da assistência social, da saúde de organizações não-governamentais [...]”. O SINALID também é utilizado na tragédia Brumadinho, bem como na pandemia de COVID-19. (CNMP, 2021 [site institucional]).

9 Na verdade, trata-se do Seminário Água, Vida, Floresta e Direitos Humanos, que já contou com 5 encontros (o último realizado em 2018. Trata-se de evento promovido pelo CNMP, pela Procuradoria-Geral da República e pela Escola Superior do Ministério Público. A sua finalidade seria "[...] discutir os avanços e desafios da proteção ambiental no Brasil e no mundo à luz dos direitos humanos. " Para outros detalhes a respeito de sua 5ª edição: CNMP, 2018.

10 O Projeto Água para o Futuro teria sido criado pelo Ministério Público de Mato Grosso, pela concessionária de Águas de Cuiabá, pelo Instituto Ação Verde e pela Universidade Federal de Mato Grosso (UFMT). A finalidade do projeto seria "[...] garantir o abastecimento de água com qualidade e quantidade para a população [...]. Para outros detalhes, ver: G1, 2018.

${ }^{11}$ O Justiça Plena foi um projeto criado, no ano de 2010, para monitorar e dar transparência ao andamento de processos de grande repercussão social. A iniciativa contou com oito protagonistas: o Ministério da Justiça (MJ), o Conselho Nacional de Justiça (CNJ), a AdvocaciaGeral da União (AGU), a Secretaria de Direitos Humanos (SDH), o Conselho Nacional do Ministério Público (CNMP), a Ordem dos Advogados do Brasil (OAB), a Defensoria Pública da União e dos Estados e a Procuradoria Federal dos Direitos do Cidadão (PFDC). (CNJ, 2021 [site institucional]). 
$\overline{\text { busca por uma aproximação social. Por aproximação social entendemos o sentido }}$ de oferecer à sociedade uma resposta - interinstitucional - para o enfrentamento dos casos de grande repercussão e na busca de soluções rápidas.

Essas razões seriam visíveis por meio da observação de sua dinâmica operacional, que ilustrará um caráter ainda subjetivo para delimitação dos critérios de escolha dos casos a serem acompanhados pelo Observatório. Essa característica acaba por revelar a forte influência política, e não técnica, para a eleição dos casos.

\subsection{Sobre a falta de critério técnico e claro para a escolha de casos a serem acompanhados.}

A Portaria Conjunta n. 01/2019 não informa quais seriam os motivos para que apenas alguns casos sejam eleitos para acompanhamento pelo Observatório. Não há critério predeterminado para a suscitada escolha. $\mathrm{O}$ seu desenho institucional, então, permite que tais critérios sejam estabelecidos conforme o andamento dos trabalhos.

De fato, apenas no $1^{\mathrm{o}}$ Relatório Trimestral de Atividades (BRASIL, 2019c) surge a informação de que os primeiros quatro casos eleitos para acompanhamento pelo Observatório Nacional estariam vinculados à Agenda 2030, coordenada pelas Nações Unidas, para a implementação dos Objetivos de Desenvolvimento Sustentável (ODS) ${ }^{12}$.

Conforme o respectivo site institucional, a Agenda 2030 seria "[...] um plano de ação para as pessoas, o planeta e a prosperidade, que busca fortalecer a paz universal". O plano indicaria 17 Objetivos de Desenvolvimento Sustentável (ODS), bem como suas 169 metas, tudo no afã de "[...] erradicar a pobreza e promover vida digna para todos, dentro dos limites do planeta" (ONU, 2021 [site institucional]).

Não há dúvidas que a eleição de casos voltados ao 'fortalecimento da paz universal', à erradicação da pobreza e à promoção da dignidade de todos seria de bom alvitre. O problema está no fato de que tais escopos não são exemplos de critérios técnicos para os fins colimados: se o ponto de partida para a paz universal for a pacificação social, a extinção da pobreza e a promoção da dignidade em cada Estado aderente à Agenda 2030, então o correto seria que o Observatório acompanhasse todos os casos levados ao Poder Judiciário, na medida em que a pacificação social e a promoção do bem comum - o que inclui a

\footnotetext{
${ }^{12}$ Os suscitados ODS seriam os seguintes: (i) Erradicação da pobreza; (ii) Fome zero e agricultura sustentável; (iii) Saúde e bem-estar; (iv) Educação da qualidade; (v) Igualdade de gênero; (vi) Água potável e saneamento; (vii) Energia acessível e limpa; (viii) Trabalho decente e crescimento econômico; (ix) Indústria, inovação e infraestrutura; (x) Redução das desigualdades; (xi) Cidades e comunidades sustentáveis; (xii) Consumo e produção responsáveis; (xiii) Ação contra a mudança global do clima; (xiv) Vida na água; (xv) Vida terrestre; (xvi) Paz, justiça e instituições eficazes; (xvii) Parcerias e meios de implementação (ONU, 2021 [site institucional]).
} 
POLÍTICOS

erradicação da pobreza e promoção da dignidade ${ }^{13}$ - são o escopo da atividade jurisdicional.

Para além de tais objeções, a escolha da Agenda 2030 como parâmetro para seleção dos casos também reúne obstáculos em sua aplicação prática.

Os quatro casos que ensejaram a criação do Observatório foram os seguintes:

a) Rompimento da Barragem na Mina do Córrego do Feijão, ocorrido em Brumadinho/MG

b) Rompimento da Barragem do Fundão, ocorrido em Mariana/MG

c) Incêndio na Boate Kiss, ocorrido sem Santa Maria/RS

d) Chacina ocorrida em Unaí/MG

Conforme o $1^{\mathrm{o}}$ Relatório Trimestral, o critério de escolha dos suscitados casos teria sido (i) o advento de tragédia, que poderia ter sido evitada; (ii) a necessidade de proteção da água, conclusão esta que pode ser extraída do Relatório em apreço:

Os quatro casos têm em comum a tragédia da perda de vidas humanas que poderiam ser evitadas, vítimas direta ou indiretamente afetadas e a necessidade de proteção à água (ODS 6), cuja contaminação coloca em risco a saúde das pessoas, além do elevado impacto à sustentabilidade do país (BRASIL, 2019a, p. $5)$.

No relatório, consta expressamente que o escopo seria a implementação das ODS 16 (Paz, justiça e instituições eficazes); 17 (Parcerias e meios de implementação), 11 (Cidades e comunidades sustentáveis) e 6 (Água potável e saneamento) ${ }^{14}$.

No $2^{\text {o }}$ Relatório Trimestral (2019b) acrescentou-se o Caso Pinheiro/AL aos quatro anteriores, decisão obtida por unanimidade pelos integrantes do Observatório após informações sobre o assunto apresentadas ao grupo pela

${ }^{13}$ A redação expressa do art. $8^{\text {o }}$ do Código de Processo Civil (CPC) é exatamente neste sentido. Confira-se: "Art. 8 ${ }^{\text {o }}$ Ao aplicar o ordenamento jurídico, o juiz atenderá aos fins sociais e às exigências do bem comum, resguardando e promovendo a dignidade da pessoa humana e observando a proporcionalidade, a razoabilidade, a legalidade, a publicidade e a eficiência.".

14 "Os quatro assuntos escolhidos pelo Observatório como prioritários para atuação inicial estão em conformidade com os temas tratados pelo Brasil na Agenda Global 2030, que vem sendo coordenada pelas Nações Unidas em 193 países, em especial, o Objetivo de Desenvolvimento Sustentável (ODS) 16 - que trata da Paz, Justiça e Instituições Eficazes; além do ODS 17 - que trata de Parcerias e Meios de Implementação, tendo como uma das metas "apoiar o desenvolvimento de capacidades em estatística nos países em desenvolvimento"; do ODS 11 Tornar as cidades e os assentamentos humanos inclusivos, seguros, resilientes e sustentáveis e desenvolver e implementar, de acordo com o Marco de Sendai para a Redução do Risco de Desastres 2015-2030, o gerenciamento holístico do risco de desastres em todos os níveis". (BRASIL, 2019a, p. 5). 
procuradora da República em Alagoas Raquel Teixeira na $6^{\mathrm{a}}$ Reunião, ocorrida em 14 de maio de 2019 (BRASIL, 2019d, p. 11).

Após a incorporação do Caso Pinheiro/AL foram firmados, em 2020, 10 temáticas de interesse: (i) Coronavírus - COVID19, (ii) Chacina de Unaí, (iii) Incêndio Boate Kiss. (iv) Barragem de Fundão, (v) Barragem Mina Córrego do Feijão, (vi) Caso Pinheiro, (vii) Segurança Pública, (viii) Migrantes e Refugiados, (ix) PPI da Amazônia, e (x) Proteção aos Povos Indígenas e ODS 15.

Na versão anterior da plataforma utilizada por essa pesquisa, que não está mais disponível online, alguns casos previam uma descrição de justificativa que continha o respectivo ODS e justificativas amplas sobre o número de pessoas envolvidas ou questões que atestem a complexidade da causa ${ }^{15}$. Todavia, ainda assim não continham justificativas que explicassem a priorização seletiva ou por representatividade dos casos dentro do território nacional, por região, ou por grupo vulnerável - critérios que poderiam ser utilizados pelo Observatório para a priorização de casos.

No $3^{\text {o }}$ Relatório Trimestral, emitido em 2020, o Observatório explica que, por conta da complexidade e os danos a direitos coletivos, foram escolhidos os quatro casos inaugurais e que, posteriormente, "com o desenvolvimento de suas atividades, o Observatório Nacional decidiu por incluir outros temas para acompanhamento, haja vista sua relevância e repercussão na sociedade" (BRASIL, 2020, p. 7).

Com a mudança de plataforma no primeiro trimestre de 2021, notou-se também que foram consolidados 16 temas como de escopo do Observatório, também sem explicações mais aprofundadas já que não foram atualizados os três

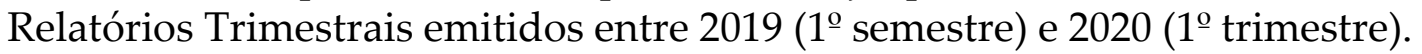

Constituem focos do Observatório em 2021: a) pandemia pela COVID-19; b) proteção aos povos indígenas, c) desflorestamento da Amazônia Legal, d) excesso ou escassez de água e ausência de saneamento, e) obras públicas paralisadas, f) desastre com barragem no município de Mariana/MG, g) desastre com barragem no município de Brumadinho/MG, h) risco de desastre geológico em bairros do município de Maceió/AL, i) regularização fundiária do MATOPIBA (Maranhão, Tocantins, Piauí e Bahia), j) meio ambiente no município de Autazes (AM), k) migrações e refúgios, 1) igualdade racial, $\mathrm{m}$ ) processos acompanhados por Cortes Internacionais ou Justiça Plena, n) homicídios contra meninas no município de

\footnotetext{
${ }^{15}$ Como exemplo: "Os integrantes do Observatório Nacional decidiram no dia 14.5.2019, durante a $6^{\mathrm{a}}$ reunião, incluir a situação de Pinheiro/AL entre os temas em acompanhamento pelo grupo. A região, que abriga cerca de 20 mil imóveis e pode atingir 42 mil pessoas segundo estimativa, apresenta uma série de rachaduras nas construções e no asfalto, além de grandes crateras pelas ruas", descrição do caso Pinheiro/AL que era disponibilizado no hiperlink: https://observatorionacional.cnj.jus.br/observatorionacional/index.php/caso-pinheiro/descricaopinheiro . Acesso em: 03 mar. 2021. [link indisponível]
} 
POLÍTICOS

Fortaleza/CE, o) chacina no município de Unaí/MG, p) incêndio da boate Kiss no município de Santa Maria/RS (BRASIL, 2021).

É possível perceber, assim, que a escolha dos 16 temas atualmente considerados pela instância não é especificamente abordada em nenhum relatório, documento técnico ou normativo. Aos 10 anteriores, excluiu-se o tema "Segurança Pública" e somaram-se os seguintes: i) água, ii) obras públicas paralisadas, iii) regularização fundiária - "MATOPIBA", iv) meio ambiente - Autazes/AM, v) igualdade racial, vi) processos de Cortes Internacionais/Justiça Plena, vii) homicídios contra meninas - Fortaleza/CE.

Tais alterações constantes e sem justificativas claras dos casos acompanhados pelo Observatório nos remete à inexistência de um critério objetivo e claro para a identificação dos casos de maior repercussão pelas instituições e sua respectiva priorização. Em primeiro lugar, quatro casos; depois, 10 casos e, agora, excluemse temas antes tidos como centrais (como Segurança Pública, por exemplo) e entram novos casos somando 16 temáticas.

Tais alterações levam a crer que existiria, talvez, uma compreensão difusa do clamor social relacionado aos temas acompanhados pelo Observatório, mas ainda sem um rigor técnico no detalhamento de como e em que medida tais casos terão um tratamento diferenciado de outros ou quais as qualidades dos casos que os deslocam para esse espaço privilegiado de acompanhamento. Por exemplo, não estão presentes, no rol de casos em acompanhamento, o derramamento de óleo que afetou a costa nordestina em agosto de 2019, ora com acusações contra organizações ambientais, ora com acusações contra governos estrangeiros e empresas, e com impactos ao turismo e à atividade pesqueira da região - temática com grande proximidade tanto em relação aos desastres tecnológicos da Bacia do Rio Doce e da Bacia do Rio Paraopeba, ocorridos em 2015 e 2019, quanto à complexidade socioeconômica e socioambiental para reparação dos danos causados (ODS 11) (WWF, 2019).

Não consta do rol de casos acompanhados pelo Observatório as questões referentes à litigância climática (ODS 13), já suscitada em casos no Supremo Tribunal Federal ${ }^{16}$, além das severas pressões estrangeiras, especialmente europeias, para que o Brasil adote outro rumo quanto ao tratamento das questões ambientais.

Também não há acompanhamento de casos relacionados a desastres causados por omissão no dever de tutela de menores, como o incêndio no Centro de

\footnotetext{
${ }^{16}$ A ação de Arguição de Descumprimento de Preceito Fundamental (ADPF) 708, sobre o Fundo Clima, foi proposta por quatro partidos políticos (PT, PSOL, PSB e Rede) em face da União Federal. A audiência pública sobre o tema, convocada pelo Min. Relator Luís Roberto Barroso, foi realizada em dois dias, em que foram ouvidos 66 especialistas: cientistas, ambientalistas, indígenas, empresários, economistas do meio ambiente, pesquisadores, parlamentares e representantes do governo federal e de governos estaduais em setembro de 2019. Disponível em: http://www.stf.jus.br/
} 
Treinamentos do Clube de Regatas do Flamengo "Ninho do Urubu", no Rio de Janeiro/RJ, na madrugada do dia 8 de fevereiro de 2019, que vitimou 10 adolescentes ${ }^{17}$. Tal caso poderia ter sido incluído, tendo em vista que corresponde ao ODS 16.

Na ausência da publicização de um critério objetivo, remanescem justificativas não tão sólidas para o enfrentamento e priorização de grupos e comunidades afetadas por situações complexas. Ainda que a premissa seja o enquadramento dos temas nos ODS, e pela descrição da natureza difusa e alto número de atingidos, não parecem esses critérios suficientes para a escolha dos temas. Essa omissão poderia, se não bem direcionada, acabar levando a uma seleção dos casos baseada nas conveniências políticas ou sociais de cada ano - gastando-se, assim, tempo e recursos sem quaisquer indícios de respostas sólidas ou de um enfrentamento coerente e eficaz dessas questões sensíveis à realidade nacional.

Esta conclusão é reforçada pelas explicações apresentadas pelo então presidente do Conselho Nacional de Justiça, Min. Dias Toffoli, e pela então presidente do Conselho Nacional do Ministério Público e Procuradora-Geral da República, Raquel Dodge, para a criação do Observatório, mencionadas no início desse artigo.

Neste contexto, o liame a unir os casos pincelados pelo Observatório seria a morosidade na apuração dos fatos e das respectivas responsabilidades, todavia, questiona-se se, para isso, a estrutura de controle existente (legal, judicial e administrativa) já não bastaria. Kerche, Oliveira e Couto (2020) questionam o papel das Corregedorias como órgãos fiscalizadores e seu papel na prestação de contas à sociedade, mas reforçam seu papel como estrutura administrativa de gestão de tarefas:

$\mathrm{Na}$ democracia, atores e agências prestam contas de seus atos a outros atores e agências, podendo ser punidos ou premiados por sua atuação. Para que a accountability seja efetiva, são necessárias autonomia e independência organizacional do fiscalizador em relação ao fiscalizado. Assim, corregedorias, embora cumpram papel relevante na organização interna e possam colaborar com incentivos para a criação de uma política institucional, não funcionam efetivamente como instrumentos de accountability democrática justamente porque o corregedor mantém laços com aqueles que devem ser fiscalizados. São, quando muito, órgãos de controle interno, ou de accountability administrativa, que asseguram uma melhor gestão e o cumprimento diligente de

\footnotetext{
17 Sobre o tema, a denúncia sobre o incêndio no Ninho do Urubu apresentada pelo Ministério Público do Rio de Janeiro. MPRJ denuncia 11 pessoas pelo incêndio que provocou a morte de dez adolescentes no Ninho do Urubu, Publicado em 15/01/2021 16:46. Disponível em: http://www.mprj.mp.br/home/-/detalhe-noticia/visualizar/99605
}

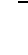


POLÍTICOS

tarefas, mas não implicam necessariamente prestação de contas à sociedade (Poulsen, 2009; Schedler, Diamond, \& Plattner, 1999) (KERCHE, OLIVEIRA, COUTO, 2020, p. 1335).

Ademais, as Corregedorias Gerais de Justiça, Ouvidorias e os próprios Conselhos Nacionais, além da imprensa, já efetuam o acompanhamento de casos de repercussão social.

Por outro lado, o fato de o Observatório buscar implementar os objetivos (ODS) previstos na Agenda 2030 não é exatamente uma novidade: todos aqueles desideratos se incluem no afã de criar uma sociedade livre, justa e solidária, garantindo-se o desenvolvimento nacional, com erradicação da pobreza e redução das desigualdades sociais e regionais, promovendo o bem de todos, sem preconceitos. Neste contexto, não aparenta que a adoção dos objetivos constantes da Agenda 2030 seja algo que já não estivesse previsto no texto constitucional.

De todo o exposto, a pergunta: qual a justificativa para mais uma instância técnica de priorização e monitoramento? Que priorização o Observatório realiza e qual a justificativa para que tais casos tenham um maior investimento de recursos humanos e sociais para seu acompanhamento e solução? Em que medida o clamor social muda as perspectivas de monitoramento e quais respostas serão dadas ao final dessa iniciativa - antes que ela mude de nome e se transforme em nova instância?

Talvez, dos trabalhos realizados pelo Observatório, seja possível visualizar quais sugestões foram por ele apresentadas. Espera-se que, em dois anos, o Observatório tenha sido capaz de demonstrar por que ele, e não os demais órgãos de supervisão (Corregedorias, Ouvidorias e os próprios CNJ e CNMP), ofertaria as melhores práticas e soluções.

\section{EXPOSIÇÃO DAS BOAS PRÁTICAS E SOLUÇÕES APRESENTADAS PELO OBSERVATÓRIO}

Como já informado, o Primeiro Relatório Trimestral, elaborado em 30 de abril de 2019, teve foco em 4 casos, a saber: a) Barragem na Mina do Córrego do Feijão - Brumadinho/MG; b) Barragem de Fundão - Mariana/MG; c) Boate Kiss - Santa Maria/RS; e d) Chacina de Auditores do Trabalho - Unaí/MG. Neste documento, após a apresentação de um relatório sucinto sobre cada um desses casos (data e local do evento, identificação da estrutura judiciária envolvida, número de vítimas e descrição sumária do ocorrido), sobrevém a identificação daquele que seria, dentre os demais, o caso prioritário e as razões para tanto: o caso de Brumadinho, em razão de seu grande número de vítimas (BRASIL, 2019a, p. 10).

Definido o caso, o documento informa que teriam sido realizadas cinco reuniões quinzenais entre os Presidentes dos Conselhos (CNJ e CNMP) e seus integrantes. Tais reuniões tiveram início em 05 de fevereiro de 2019 e se estenderam até 09/04/2019 (BRASIL, 2019c, p. 11). Outras reuniões foram 
realizadas, mas desta vez com agências reguladoras ${ }^{18}$ e com o Conselho Superior da Justiça do Trabalho ${ }^{19}$. Dos quatro casos analisados pelo Observatório, apenas teria sido feita visita in loco na cidade de Brumadinho ${ }^{20}$. Com relação à participação social nessas reuniões inaugurais, é citada uma visita técnica ao município de Brumadinho/MG em 06/02/2019 para apoio institucional aos membros locais (BRASIL, 2019c, p. 12). Não há registro de consulta ou escuta da sociedade civil no documento.

No que tange à Chacina de Unaí e à Barragem do Fundão - Mariana/MG, o Observatório identificou a existência de processos judiciais já em andamento. Quanto a esses processos, as providências concretas teriam sido (i) a imposição de "Especial acompanhamento, quanto à observância da razoável duração do processo e monitoramento do prazo" e (ii) "priorização no julgamento". Também foi determinada a digitalização de um dos autos do processo que tramitariam perante o Tribunal Regional Federal da 1aㅡ Região (BRASIL, 2019c, p. 13).

O Relatório também destaca a adoção de Tabelas Processuais Unificadas. Estruturadas conforme a Resolução CNJ 46/2007, as finalidades das Tabelas seriam (i) "[...] identificar com rapidez os processos judiciais relacionados aos desastres; (ii) viabilizar a obtenção de "[...] relatórios estatísticos automáticos pelos tribunais [...], além de (iii) [...] consolidar as informações no CNJ" (BRASIL, 2019c, p. 13).

Outro destaque apontado no Relatório consiste na criação do Portal do Observatório, com a finalidade de "[...] estabelecer um canal de interlocução entre o sistema de Justiça e a sociedade, a fim de dar visibilidade à metodologia de sistematização de dados com a participação efetiva e colaborativa dos tribunais $[\ldots]^{\prime \prime 21}$

18 "Foram realizadas duas reuniões na sede do CNJ para entender à perspectiva de atuação das Agências Reguladoras envolvidas com as situações das barragens, para subsidiar os trabalhos do Observatório. As agências diretamente ligadas às situações de rompimento de barragens são: Agência Nacional de Mineração (ANM), a Agência Nacional de Águas (ANA) e a Agência Nacional de Energia Elétrica (Aneel). A ANA disponibilizou o Relatório de Segurança de Barragens 20171 que consolida os dados das três agências quanto à situação das barragens no país." (BRASIL, 2019a, p. 11).

${ }_{19}$ O Conselho Superior da Justiça do Trabalho está previsto no art. 111-A da Constituição Federal e tem por objetivos "[...] supervisão administrativa, orçamentária, financeira e patrimonial da Justiça do Trabalho de primeiro e segundo graus, como órgão central do sistema, cujas decisões terão efeito vinculante."

${ }^{20}$ Outras providências adotadas teriam sido a expedição de ofícios ao: i) Tribunal Regional Federal da 1aㅡ Região, ii) Tribunal Regional do Trabalho da $3^{\text {a }}$ Região, iii) Tribunal de Justiça do Estado de Minas Gerais, iv) Tribunal Regional Federal da $4^{\mathrm{a}}$ Região, v) Tribunal Regional do Trabalho da $4^{\mathrm{a}}$ Região vi) Tribunal de Justiça do Estado do Rio Grande do Sul, com a finalidade de obtenção de informações processuais. (BRASIL, 2019a, p. 12).

${ }^{21}$ Com a criação do Portal, espera-se obter os dados necessários à realização de três pesquisas: a) Pesquisa sobre o perfil das vítimas fatais, b) Pesquisa sobre as principais notícias veiculadas pelos Tribunais, c) Pesquisa sobre o número único das ações judicializadas (Resolução CNJ n. 
POLÍTICOS

Assim, temos três eixos de atividades propostas nesse primeiro relatório: a) reuniões de monitoramento dos casos com autoridades responsáveis, b) determinação de priorizações e encaminhamentos relativos à tramitação dos autos relacionados, c) gestão arquivista e documental dos processos via adoção de "Tabelas Processuais Unificadas". Não consta expressamente, em tais relatórios, nenhuma sugestão de boas práticas ou soluções para os problemas existentes.

O Segundo Relatório Trimestral (referente ao período maio a julho/2019) traz novas informações sobre os casos já relacionados no Primeiro Relatório Trimestral e acrescenta o caso do Bairro de Pinheiros, em Maceió/AL. O Relatório também traz a suma do teor das reuniões efetivadas no respectivo trimestre, bem como das atas e respectivos documentos (BRASIL, 2019d, p. 11-14). Neste relatório são indicadas duas participações de membros da sociedade civil nas reuniões sobre o caso Boate Kiss (representantes de vítimas e atingidos), e o rompimento da barragem de Fundão - Mariana/MG (representantes do MAB - Movimento dos Atingidos por Barragens) (BRASIL, 2019d, p. 11-12).

É interessante observar o destaque dado ao acompanhamento das ações do Observatório pelas Secretarias de Comunicação Social do CNMP e do CNJ. O Relatório é categórico ao informar sobre o envio de releases à imprensa, “[...] com o objetivo de dar máxima publicização e repercussão às pautas" (BRASIL, 2019d, p. 15)

Sendo assim, o Segundo Relatório reforça ainda mais a ideia de publicização das pautas e diálogo social a respeito dos temas, inclusive pelo reforço da finalidade do projeto - a "[...] proteção de direitos coletivos e na efetividade do acesso à Justiça" e reafirma ser incumbência do Observatório organizar e promover a integração entre os membros do Poder Judiciário e do Ministério Público "[...] e entre outros agentes públicos envolvidos na tramitação dos feitos judiciais e extrajudiciais" pelo "[...] intercâmbio entre instituições e especialistas, realizar reuniões periódicas e promover a cooperação entre as diversas instituições" (BRASIL, 2019d, p. 29-35).

Dentre as reuniões documentadas no Segundo Relatório Trimestral, chama a atenção o teor da Ata da 1a Reunião Extraordinária do Observatório. Ao se referir ao Caso do Bairro Pinheiro em Maceió/AL, o Ministro Dias Toffoli afirma categoricamente que o Observatório visa "chamar a atenção" para casos de grande impacto "evitando mais desastres" (BRASIL, 2019d, p. 34).

O Terceiro Relatório Trimestral disponível no site é referente ao primeiro trimestre de 2020 - não tendo sido divulgados os relatórios subsequentes de 2019, e retoma os novos casos em acompanhamento pela iniciativa, indica os objetivos ODS referentes a eles, e sumariza o status atual dos casos e links de acesso a dados já coletados pela plataforma. Com relação à participação da sociedade civil,

65/2008 e Resolução CNJ n. 235/2016) e procedimentos em trâmite no ministério, que permite a visualização das ações por meio de painel eletrônico interativo, denominado Painel de Acompanhamento de Causas de Grande Repercussão. (BRASIL, 2019a, p. 14). 
o relatório indica maior participação que aquela prevista em relatórios anteriores, em temas como: proteção aos povos indígenas, risco de desastre geológico em Maceió/AL e desflorestamento da Amazônia Legal; todavia, não aponta critérios ou regras para participação social e como foram selecionados os grupos e indivíduos ouvidos (BRASIL, 2020).

Com relação à chamada "Nova Plataforma do Observatório Nacional" (BRASIL, 2020, p. 28-ss) reforça-se que nova plataforma de monitoramento terá melhorias:

Os casos estarão mais visíveis, os menus mais amigáveis e será de fácil utilização e navegação. Em breve estará disponível para o público, com vistas a ampliar a transparência e propiciar maior controle social sobre as questões ambientais, econômicas e sociais de alta complexidade e grande impacto e repercussão (BRASIL, 2020, p. 28).

Além dos relatórios trimestrais acima expostos, também foi elaborado um Relatório Conjunto de Atividades, cujo teor abrangeria os atos praticados no período compreendido entre janeiro e abril de 2019. ${ }^{22}$ Com redação muito próxima àquela utilizada no Segundo Relatório Trimestral, o Relatório Conjunto condensa as atividades praticadas no interregno. Vale ressaltar que, ao longo da pesquisa, esse documento tornou-se indisponível na nova plataforma do Observatório.

Sobre as omissões de informações entre 2019 e 2021, é importante destacar que após consulta ao Conselho Nacional do Ministério Público via Lei de Acesso à Informação (LAI), foi informado que "os relatórios produzidos pelo Observatório são aqueles disponibilizados na página do colegiado" ${ }^{23}$.

A ausência de critérios claros de seleção de casos, a escassez de informações disponibilizadas pelos relatórios das atividades executadas no período, as circunstâncias da criação do Observatório e sua atuação nos primeiros anos ostentam traços de uma estratégia de comunicação dos Conselhos Nacionais para a obtenção de apoio social e legitimidade, mais do que o acompanhamento de teses jurídicas potencialmente inovadoras, como será indicado a partir de perspectivas estrangeiras a seguir.

22 O documento estava disponível pelo link até o início de 2021: https://observatorionacional.cnj.jus.br/observatorionacional/images/observatorio/relatorio/Relatr io de Atividades - Observatrio Nacional 28-06.pdf . Acesso em: 03 mar. 2021 [link indisponível].

${ }^{23}$ Consulta realizada via Ouvidoria Nacional do Ministério Público - resposta em 12/01/2020: "Esclarecemos que após coleta de informações nos setores do CNMP, informamos que os relatórios produzidos pelo Observatório são aqueles disponibilizados na página do colegiado". 
Instituições boas não melhoram pessoas deletérias, mas instituições ruins, com toda a certeza, potencializam os efeitos de pessoas deletérias. Por si só, tal circunstância já torna imperiosa a sua substituição por instituições melhores.

\section{ANÁlise CRÍTICA dOS RELATÓRIOS ELABORADOS PELO OBSERVATÓRIO, O ESCOPO DE GANHO DE LEGITIMIDADE E DÉFICIT DE PARTICIPAÇÃO SOCIAL}

O cotejar dos relatórios acima pincelados com o desenho institucional da iniciativa demonstra que, em dois anos de trabalho, o Observatório não apresentou uma proposta concreta para a solução para os problemas de maior repercussão nacional, já que foram apresentadas novas instâncias de sistematização de informações e foram sumarizadas as reuniões interinstitucionais voltadas ao acompanhamento dos casos. Todavia, os esforços da iniciativa não vieram à tona no sentido da resolução das questões apresentadas até o momento.

Os relatórios não são claros sobre os outcomes do trabalho de integração entre membros do Poder Judiciário, do Ministério Público e de outras instituições, apesar das interações parecerem um forte investimento da iniciativa e um dos seus principais mecanismos de mobilização destes atores em prol da resolução dos casos.

Não obstante as dúvidas que se apresentem sobre a efetividade da instância, é possível que as consecuções dos objetivos de aprimoramento da prestação jurisdicional talvez demandem apenas tempo para serem implementados. A adoção de medidas eficientes para a solução de casos de grande repercussão, de fato, não ocorreria do dia para a noite. Ainda assim, a crítica prevalece porque não há sinal de alguma providência mais efetiva para a implementação dos desideratos expostos na Portaria Conjunta n. 01/2019. Tal como estão, os trabalhos realizados pouco justificam a atuação do Observatório e seus enfoques foram alterados por pelo menos três vezes desde sua criação - sem resultados claros do impacto da iniciativa para o tratamento e avanço da reparação nessas situações.

Nessa linha, questiona-se se a criação e desenvolvimento do Observatório Nacional estaria mais alinhada a uma justificativa de comunicação de ações e relacionamento com a opinião pública, conforme sugerido pela literatura que explora os mecanismos concretos de legitimação de cortes constitucionais.

O conceito admitido aqui é o exposto por Jeffrey K. Staton que, utilizando-se do conceito de legitimidade elaborado por Caldeira e Gibson (1992), estabeleceu:

A legitimidade é conceitualizada como o apoio público difuso ou o profundo comprometimento com a integridade institucional do judiciário (Caldeira e Gibson 1992, 638). O conceito requer um comprometimento para defender a estrutura institucional e a autoridade do judiciário, mesmo se uma decisão em particular for 
contra os interesses pessoais (STATON, 2010, p. 24, tradução nossa).

E ainda "sob esta ótica, as pessoas apoiam as cortes quando elas acreditam que assim 'farão a coisa certa" (STATON, 2010, p. 24, tradução nossa).

Este apoio público é o combustível que impulsiona os políticos aos cargos almejados. A métrica deste apoio é a quantidade de votos. Se estes votos forem suficientes, o candidato estará eleito. Quanto maior a quantidade de votos, maior a sua força política. O mecanismo que ilustra a importância do apoio público está evidenciado acima: não há dúvida sobre o seu funcionamento, no contexto das eleições majoritárias.

Ocorre que esta instância não explica adequadamente as razões pelas quais os integrantes de um Poder apolítico se interessariam por uma melhor comunicação com a sociedade. Afinal, por que juízes, desembargadores, ministros ou conselheiros, que independem do voto popular para se manterem em seus cargos, buscariam apoio político?

A lógica é simples: na medida em que um determinado órgão não-político goza de apoio da sociedade, a adoção de práticas contrárias aos interesses daquele órgão significaria assumir o risco de cair no desgosto daquela parcela da sociedade que apoia o referido órgão. Este fato pode ensejar o desgaste da base eleitoral de um determinado político, com risco de não conseguir se eleger. Neste contexto, quanto maior o apoio da sociedade a um determinado órgão nãopolítico, menor a probabilidade de os agentes políticos desrespeitá-lo. Neste sentido, Staton traz a premissa de que, ao gozar de suficiente legitimidade, as decisões judiciais seriam impostas aos demais Poderes (Executivo e Legislativo), sem risco de serem desobedecidas:

Em suma, os acadêmicos identificam duas condições sob as quais nós podemos invocar o público como um mecanismo de execução indireta das para as decisões judiciais: (1) as cortes precisam gozar de legitimidade suficiente para fazer desinteressante qualquer ato de desobediência às suas decisões, e (2) as pessoas precisam estar suficiente informadas sobre as atividades das cortes para que possam monitorar casos potenciais de desobediência às ordens judiciais (STATON, 2010, p. 25).

E ainda:

Sem apoio público, os ocupantes de cargos públicos irão visualizar a inexistência de custos para desobedecer às decisões judiciais, circunstância esta que fortalecerá o incentivo para que o 
Judiciário resolva os conflitos de forma prudente (STATON, 2010, p. 25).

Nesta linha de pensamento, a mera previsão legal, ainda que lançada na Constituição, não conferiria plena certeza de eficácia das decisões judiciais. A legalidade, destituída da legitimidade conferida pela opinião pública, seria facilmente ignorada por outros interesses.

Essa hipótese é explorada por diversos trabalhos na literatura estrangeira ${ }^{24}$. Utilizaremos nessa linha os recentes trabalhos de Vanberg (2005) e Staton (2010) que evidenciam ganhos estratégicos e reputacionais advindos de uma boa-relação entre Cortes e a opinião pública.

A obra de Georg Vanberg (2005) focada na análise da Corte Constitucional alemã (German Federal Constitucional Court - FCC, Tribunal Constitucional Federal - TCF) dialoga com Staton (2010) e contribui para a compreensão teórica e empírica de como as maiorias do governo, a opinião pública e a transparência do ambiente político produzem uma influência central na elaboração das decisões judiciais e sua implementação. Porque decisões judiciais frequentemente requerem ou induzem uma resposta por parte de outros atores governamentais, Cortes constitucionais enfrentam um potencial "problema de implementação" (VANBERG, 2005, p. 8, tradução nossa).

Sua obra vai buscar responder à pergunta sobre quais as circunstâncias em que Cortes conseguem superar esses problemas de implementação e como elas interagem de forma estratégica com atores políticos e com a opinião pública para isso. O olhar estratégico em Vanberg é central para classificá-lo como parte de uma literatura que entende que o Judiciário precisa antecipar determinados movimentos e ações dos poderes políticos para ser bem-sucedido na sua atuação.

Vanberg deixa essa perspectiva clara quando coloca que adota "um olhar estratégico que enfatiza as interdependências mútuas entre maiorias legislativas e Cortes constitucionais" (VANBERG, 2005, p. 12). Sobre esse ponto o autor coloca que as considerações estratégicas da parte do Judiciário receberam menor atenção pela literatura, dado que tradicionalmente as Cortes são vistas como "além da política" e suas decisões têm sido tratadas como textos legais isoladamente de contextos políticos. Por isso enfatiza que, além da opinião pública servir ao suporte das decisões da Corte, a mesma opinião pública vai condenar poderes políticos quando a desrespeita, tratando do impacto de perda de reputação e popularidade do legislativo que descumpre decisão judicial (VANBERG, 2005, p. 14).

\footnotetext{
${ }^{24} \mathrm{~A}$ esse exemplo, autores que trabalham a discussão sobre autoridade de cortes na perspectiva da judicial politics na interrelação com sociedade e demais poderes/instituições: Gretchen Helmke em Courts under Constraints Judges Generals and Presidents (2004) e Constitutional Courts as Mediators de Julio Ríos-Figueroa (2016).
} 
Esta estratégia foi observada por Staton por ocasião do embate entre o governo Zedillo e a Suprema Corte Mexicana (Suprema Corte de Justicia Nacional $-\mathrm{SCJN})$.

Conforme a narrativa apresentada por Staton (2010), a câmara baixa mexicana queria ter acesso a um trust, por acreditar que as respectivas informações poderiam revelar um esquema ilícito de financiamento eleitoral do presidente Ernesto Zedillo. Ocorre que o Presidente Zedillo negou acesso às informações, de maneira que a Câmara acionou a Suprema Corte. O detalhe está no fato de que esta seria a primeira vez que a Suprema Corte Mexicana entraria em atrito em caso tão sensível com o presidente. Todos os ministros se reportaram à mídia, com maior destaque ao presidente da corte, Genaro Góngora Pimentel. O resultado desta ampla divulgação dos fatos e da atividade desenvolvida pela Suprema Corte foi a construção de uma opinião pública favorável à atuação judicial, fato este inédito, na medida em que, até então, a Suprema Corte era vista como um mero apêndice do Poder Executivo ${ }^{25}$. O resultado foi a imediata apresentação dos documentos pelo governo Zedillo, em cumprimento à ordem judicial:

[...] A Câmara dos Deputados requisitou informações detalhadas sobre o trust em questão, incluindo os nomes dos servidores que efetivaram cada transação e notas sobre o processo de tomada de decisão por meio do qual foram efetivadas as intervenções nos bancos. Zedillo recusou todas estas requisições, o que levou a Câmara a postular perante a Corte Suprema, para que as informações solicitadas fossem prestadas.

O pedido da Câmara foi atendido por decisão unânime da Corte. A decisão observou que os artigos 73 e 74 da Constituição atribuiria ao Congresso a responsabilidade de aprovar $\mathrm{o}$ orçamento federal e supervisionar as ações tomadas pelo presidente que afetassem a dívida pública. [...] a corte promoveu agressivamente o resultado deste caso, concedendo entrevistas a toda mídia interessada em uma declaração [...]. Em algumas horas após o pronunciamento, o presidente ordenou ao seu Secretário de Finanças que as informações fossem disponibilizadas. (STATON, 2010, p. 65).

Vê-se, portanto, da pesquisa de Staton (2010) e Vanberg (2005) e dos estudos que dialogam com essas referências, que Cortes constitucionais se importam com sua relação com a opinião pública e com os demais poderes, e muitas vezes

${ }^{25}$ The first problem was society's belief that the federal judiciary was likely subservient to the executive branch, a belief that undermined the Court's legitimacy.(STATON, 2010, p. 55) 
POLÍTICOS

utilizam tais ativos de forma cruzada - inclusive operacionalizando o apoio popular de forma a constranger atores políticos a não desafiarem suas decisões. Inevitavelmente esse processo ocorre muitas vezes de forma velada, ou seja, atores políticos antecipam o apoio popular às Cortes e Cortes antecipam sua legitimidade para a tomada de decisões que interferem mais ativamente na esfera de decisão política.

Aparenta que os Conselhos Nacionais de Justiça e do Ministério Público entenderam esta lição e buscaram a conquista do apoio popular, a exemplo do que fazem outros Conselhos de Justiça ${ }^{26}$, mas por meio da atuação do Observatório.

\section{CONCLUSÃO}

No caso brasileiro, valendo-se de casos de maior repercussão e de fácil compreensão pela sociedade, ao que tudo indica, a forma de seleção dos casos e de condução das atividades do Observatório Nacional expostas nesse trabalho tem um viés de atendimento ao clamor público e a situações de grande sensibilidade nacional, apresentando-se como instância capaz de reunir soluções para casos de grande complexidade e repercussão.

A partir dos documentos técnicos e práticas analisadas foi possível identificar que, se a justificativa principal para criação do mecanismo restringe-se ao suposto déficit de resolutividade dos temas selecionados, não são apresentados os dados e as métricas que amparem esse diagnóstico. Ou ainda, caso decorra de aderência aos ODS/ONU ou às peculiares características dos casos (alto volume de pessoas atingidas ou complexidade técnico-resolutiva) tampouco estes são critérios descritos ou que possam embasar a iniciativa.

Sem o estabelecimento de critérios claros de entrada e saída, salta aos olhos as mudanças repentinas de enfoque - ao menos três grandes mudanças ao longo de dois anos de atividades - e de metodologia de trabalhos, além de baixa transparência com relação aos métodos de trabalho e priorizações temáticas mesmo internamente aos casos analisados (hoje 16 frentes de trabalho distintas e com situações concretas muito díspares, além de numerosos interlocutores da sociedade civil).

26 A preocupação dos Conselhos de Justiça europeus em obter apoio popular é perceptível da leitura dos princípios, recomendações e diretrizes da Rede Europeia dos Conselhos para o Judiciário: "Theme 15: Public confidence 80. It is essential to secure respect for the law and public confidence in the judiciary. 81. Councils for the Judiciary should monitor public confidence in the judiciary and promote measures to increase it. 82. A system should be devised and improved to research public trust and confidence in 5 areas: (a) the justice system and its basic values, (b) the courts, (c) judges and court officials, (d) decisions, judgments and rulings, and (e) EU courts, European laws and regulations. The research should be undertaken at regular intervals and the results should be freely available to the media and the public" (ENJC, 2017, p. 13). 
Ainda, com relação à participação social, como são casos de grande repercussão social e sensibilidade, estes já contam com a participação ativa de diversas associações da sociedade civis, movimentos sociais e organizações, além de grupos de universidades e think tanks que monitoram os dados e produzem relatórios técnicos sobre o tema.

Causa temor que, pela análise dos relatórios e da dinâmica de desenvolvimento das atividades desses últimos dois anos de execução da instância não haja ainda uma metodologia adequada para assegurar a participação social dos diferentes grupos - tanto na definição das priorizações quanto no tratamento e monitoramento dos temas, além da busca de soluções que atendam os interesses sociais complexos e multifacetados em jogo. Tal constatação parece apontar para um déficit de representatividade no tratamento dessas demandas de interesse público, ainda que pesquisas anteriores apontem para os benefícios derivados da parceria e colaboração entre sociedade civil e instituições do sistema de justiça na litigância estratégica ${ }^{27}$.

Ainda que os relatórios apontem para a participação de entidades civis e governamentais em reuniões, subsistem as mesmas preocupações externadas pela literatura no caso dos amici curiae e nas audiências públicas promovidas pelo STF - em especial, sobre a efetiva pluralização no uso dessas ferramentas e potencial uso como espaço para lobby (ALMEIDA, 2019; GUIMARÃES, 2020).

Após a análise dos principais documentos disponibilizados sobre $\mathrm{o}$ Observatório Nacional e um levantamento de suas principais ações e recomendações verifica-se, em resposta à pergunta de pesquisa levantada, que ainda subsistem pontos de aprimoramento necessários à iniciativa. Destacam-se os seguintes: falta de critérios claros de priorização e seleção de casos diante da diversidade amostral, ausência de transparência no método e tratamento dos casos, ausência de participação social das associações da sociedade civil e movimentos sociais e baixa resolutividade ou ausência de parâmetros claros para indicadores de eficiência e intervenção nos casos concretos. Em razão disso, coloca-se a importância de que a academia e a sociedade civil acompanhem de perto tais iniciativas para que tais esforços não tenham mera eficácia simbólica na repercussão social de eventos trágicos para a sociedade brasileira, mas sejam endereçados de forma participativa e eficiente pelo sistema de justiça.

\footnotetext{
${ }^{27}$ Nessa linha, o relatório conjunto entre a Secretaria de Reforma do Judiciário (SRJ) por meio do Centro de Estudos sobre o Sistema de Justiça e o Centro Brasileiro de Análise e Planejamento (CEBRAP), "Advocacia de Interesse Público no Brasil: a atuação das entidades de defesa de direitos da sociedade civil e sua interação com os órgãos de litígio do Estado" (BRASIL, SRJ/CEBRAP, 2013) e o Relatório Analítico Propositivo "Justiça Pesquisa: Direitos e Garantias Fundamentais. Ações Coletivas no Brasil: temas, atores e desafios na tutela coletiva" da Sociedade Brasileira de Direito Público (SBDP, 2018).
} 


\section{REFERÊNCIAS}

ALMEIDA, Eloísa Machado de. Capacidades institucionais dos amici curiae no Supremo Tribunal Federal: acessibilidade, admissibilidade e Influência. Rev. Direito Práx., Rio de Janeiro, Vol. 10, N. 1, 2019, p. 678-707.

BRASIL. Conselho Nacional de Justiça - CNJ. Projeto Justiça Plena [site institucional]. Disponível em: https://www.cnj.jus.br/programas-e-acoes/justicaplena/ Acesso em: 09 mai. 2021.

BRASIL. Conselho Nacional de Justiça - CNJ. Observatório dos Direitos Humanos do Poder Judiciário [site institucional]. Disponível em:

https://www.cnj.jus.br/observatorio/observatorio-direitos-humanos/ Acesso em: 09 mai. 2021.

BRASIL, 2019. Conselho Nacional de Justiça - CNJ. CNJ e CNMP criam observatório para dar resposta célere a catástrofes. 1 de fevereiro de 2019, Notícias CNJ / Agência CNJ de Notícias. Disponível em: https://www.cnj.jus.br/cnj-e-cnmp-criam-observatorio-para-dar-resposta-celere-acatastrofes/ Acesso em: 16 mai. 2021.

BRASIL, 2021. Conselho Nacional de Justiça - CNJ. Conselho Nacional do Ministério Público - CNMP. OBSERVATÓRIO NACIONAL Sobre Questões Ambientais, Econômicas e Sociais de Alta Complexidade e Grande Impacto e Repercussão [site institucional]. Disponível em:

https://observatorionacional.cnj.jus.br/observatorionacional/ Acesso em: 09 mai. 2021.

BRASIL, 2019a. Conselho Nacional de Justiça - CNJ. Conselho Nacional do Ministério Público - CNMP. Portaria Conjunta n. 1 de 31/01/2019. Institui o Observatório Nacional sobre Questões Ambientais, Econômicas e Sociais de Alta Complexidade e Grande Impacto e Repercussão. Disponível em:

https://atos.cnj.jus.br/atos/detalhar/atos-normativos?documento=2810 Acesso em: 09 mai. 2021.

BRASIL,2019b. Conselho Nacional de Justiça - CNJ. Conselho Nacional do Ministério Público - CNMP. Portaria Conjunta n. 3, de 11/11/2019. Altera a Portaria Conjunta CNMP/CNJ no 1, de 31 de janeiro de 2019, que instituiu o Observatório Nacional sobre Questões Ambientais, Econômicas e Sociais de Alta 
Complexidade e Grande Impacto e Repercussão. Disponível em: https://atos.cnj.jus.br/atos/detalhar/3329 Acesso em: 09 mai. 2021.

BRASIL, 2019c. Conselho Nacional de Justiça - CNJ. Conselho Nacional do Ministério Público - CNMP. 1º Relatório Trimestral de Atividades, 2019a. Disponível em:

https://observatorionacional.cnj.jus.br/observatorionacional/relatorios/ Acesso em: 09 mai. 2021.

BRASIL, 2019d. Conselho Nacional de Justiça - CNJ. Conselho Nacional do Ministério Público - CNMP. $2^{\circ}$ Relatório Trimestral de Atividades, 2019b. Disponível em:

https://observatorionacional.cnj.jus.br/observatorionacional/relatorios/ Acesso em: 09 mai. 2021.

BRASIL 2020. Conselho Nacional de Justiça - CNJ. Conselho Nacional do Ministério Público - CNMP. 3ํㅜㄹ Relatório Trimestral de Atividades, 2020. Disponível em:

https://observatorionacional.cnj.jus.br/observatorionacional/relatorios/ Acesso em: 09 mai. 2021.

BRASIL. Conselho Nacional do Ministério Público - CNMP. SINALID - Sistema Nacional de Localização e Identificação de Desaparecidos [site institucional]. Disponível em:

https://www.cnmp.mp.br/portal/institucional/comissoes/comissao-de-defesa-dosdireitos-fundamentais/sinalid/informacoes-sobre-o-

sistema\#: :text=Criado\%20a\%20partir\%20de\%20projeto\%20premiado\%20pelo\%20 Conselho,com $\% 20$ rela $\% \mathrm{C} 3 \% \mathrm{~A} 7 \% \mathrm{C} 3 \% \mathrm{A30} \% 20 \mathrm{ao} \% 20$ enfrentamento $\% 20 \mathrm{do} \% 20 \mathrm{des}$ aparecimento\%20de\%20pessoas. Acesso em: 09 mai. 2021.

BRASIL. Conselho Nacional do Ministério Público - CNMP. Inscrições prorrogadas para o seminário internacional sobre água, floresta, vida e direitos humanos. Disponível em: https://www.cnmp.mp.br/portal/todas-asnoticias/11723-inscricoes-prorrogadas-para-o-seminario-internacional-sobre-aguafloresta-vida-e-direitoshumanos?highlight=WyJzZW1pblx1MDBIMXJpbyIsIlx1MDBIMWd1YSIsInZpZG EiLCI2aWRhJy4iLCImbG9yZXNOYSIsImRpcmVpdG9zIiwiaHVtYW5vcyIsImh1b WFub3MnLCIsInNlbWluXHUwMGUxcmlvIFx1MDBIMWd1YSIsInNlbWluXHU wMGUxcmlvIFx1MDBIMWd1YSB2aWRhIiwiYWd1YSB2aWRhIiwiXHUwMGUx 
POLÍTICOS

Z3VhIHZpZGEgZmxvcmVzdGEiLCI2aWRhIGZsb3Jlc3RhIiwiZGlyZW10b3MgaH VtYW5vcyJd. Acesso em: 16 mai. 2021.

BRASIL. Secretaria de Reforma do Judiciário - SRJ. Centro Brasileiro de Análise e Planejamento - CEBRAP. Advocacia de interesse público no Brasil: a atuação das entidades de defesa de direitos da sociedade civil e sua interação com os órgãos de litígio do Estado / coordenador: José Rodrigo Rodriguez - Brasília: Ministério da Justiça, Secretaria de Reforma do Judiciário, 2013. 120 p. - (Diálogos sobre a Justiça).

BRASIL. Supremo Tribunal Federal. Arguição de Descumprimento de Preceito Fundamental (ADPF) 708. Rel. Min. Luís Roberto Barroso. Disponível em: http://www.stf.jus.br/

CALDEIRA, Gregory A., GIBSON, James L. The Etiology of Public Support for the Supreme Court. American Journal of Political Science, 36:635-64, 1992.

ENJC - European Network of Councils for the Judiciary, Distillation of ENCJ Principles, Recommendations and Guidelines (2004-2017). Disponível em: https://pgwrk-websitemedia.s3.eu-west-1.amazonaws.com/production/pwk-webencj2017-p/Reports/ENCI Distillation Report 2004 2017.pdf , Acesso em: 17 mai. 2021.

FRANCO, Ivan Candido da Silva de, \& CUNHA, Luciana Gross. O CNJ e os discursos do Direito e Desenvolvimento. Revista Direito GV, 9(2), 515-534, 2013.

G1. Projeto Água para o Futuro visa garantir a segurança hídrica de Cuiabá/MT. Publicado em 21/08/2018 às 13:18:37, Disponível em:

https://tratamentodeagua.com.br/projeto-agua-para-o-futuro/ . Fonte original: https://g1.globo.com/mt/mato-grosso/especial-publicitario/cabcuiaba/noticia/2018/08/20/projeto-agua-para-o-futuro-visa-garantir-a-segurancahidrica-de-cuiaba.ghtml Acesso em: 16 mai. 2021.

GAROUPA, Nuno. GINSBURG, Tom. Guarding the guardians: judicial councils and judicial independence, 57 American Journal of Comparative Law. 201-32, 2008. 
GUARNIERI, Carlo. Judges, their careers, and Independence. Comparative Law and Society. Reaserch Handbook in Comparative Law. Handbook Chapter. Published: 31 August 2012.

GUIMARÃES, Lívia Gil. Participação Social no STF: repensando o papel das audiências públicas. Rev. Direito Práx., Rio de Janeiro, Vol. 11, N. 01, 2020, p. 236271.

HAMMERGREN, Linn. Do judicial councils further judicial reform?: Lessons from Latin America . Rule of Law Series - Democracy and Rule of Law. Carnegie Endowment for International Peace: 28June, 2002.

HELMKE, Gretchen. Courts under Constraints: Judges, Generals, and Presidents in Argentina. New York: Cambridge University Press, 2004.

KERCHE, Fábio; OLIVEIRA, Vanessa Elias de e COUTO, Cláudio Gonçalves. Os Conselhos Nacionais de Justiça e do Ministério Público no Brasil: instrumentos de accountability? Rev. Adm. Pública [online], vol.54, n.5, 2020. pp.1334-1360. Epub 02-Nov-2020. ISSN 1982-3134.

KOZAK, Ana Paula. BARBOZA, Estefânia Maria de Queiroz. O papel do CNJ diante do reconhecimento do estado de coisas inconstitucional do sistema carcerário brasileiro na perspectiva do ativismo dialógico. Rev. Bras. Pol. Púb. [online] vol.10, n.1 (2020). p. 175-194.

ONU - Organização das Nações Unidas. A Agenda 2030 para o Desenvolvimento Sustentável [site institucional]. Disponível em : http://www.agenda2030.com.br/sobre/. Acesso em: 16 mai. 2021.

RÍOS-FIGUEROA, Julio. Constitutional Courts as Mediators: Armed Conflict, Civil-Military Relations, and the Rule of Law in Latin America. New York: Cambridge University Press, 2016.

SBDP - SOCIEDADE BRASILEIRA DE DIREITO PÚBLICO (Brasil). Ações coletivas no Brasil: temas, atores e desafios da tutela coletiva. Brasília: CNJ, 2018. 236 p. (Justiça Pesquisa). Relatório analítico propositivo. Disponível em : https://bibliotecadigital.cnj.jus.br/jspui/handle/123456789/290

STATON, Jeffrey K. Judicial Power and Strategic Communication in Mexico. New York: Cambridge University Press, 2010. 
A ViabilidADE CONSTITUCIONAL DA ADOÇÃO DO PARLAMENTARISMO NO BRASIL: O PERENE DILEMA INSTITUCIONAL BRASILEIRO EM SEUS ASPECTOS HISTÓRICOS, JURÍDICOS E POLÍTICOS

VANBERG, Georg. The politics of constitutional review in Germany. New York: Cambridge University Press, 2005.

WWF - World Wide Fund for Nature. O que se sabe até agora sobre o derramamento de óleo no Nordeste, 12/11/2019. Disponível em:

https://www.wwf.org.br/informacoes/noticias meio ambiente e natureza/?73944 OO-que-se-sabe-ate-agora-sobre-o-derramamento-de-oleo-no-Nordeste . Acesso em: 17 mai. 2021. 